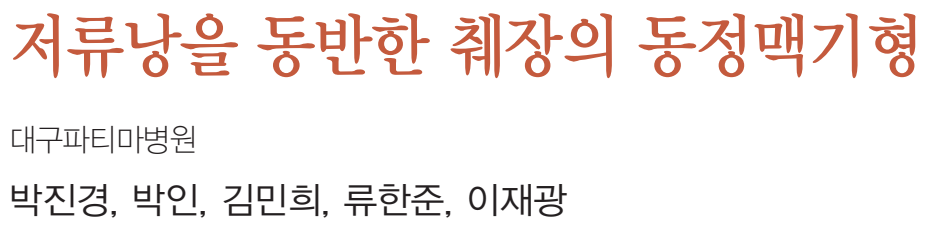

\title{
Arteriovenous Malformation with a Retention Cyst of the Pancreas
}

\author{
Jinkyung Park, In Park, Minhee Kim, Hanjun Ryu, Jae Kwang Lee \\ Division of Gastroenterology and Hepatology, Department of Internal Medicine, Daegu Fatima Hospital, Daegu, Korea
}

Arteriovenous malformation (AVM) of the pancreas is exceedingly rare, although it may be increasingly diagnosed due to the widespread use of cross-sectional imaging of the abdomen; even rarer is its association with pancreatitis. A 45-year-old male was admitted to our hospital with symptom of epigastric pain. Dynamic contrast imaging scans of the abdomen showed a focal acute pancreatitis and pancreatic AVM. The angiography findings were compatible with pancreatic AVM. The cause of abdominal pain was diagnosed by acute pancreatitis caused by pancreatic AVM, and, for definitive treatment of symptomatic pancreatic AVM, distal pancreatectomy with splenectomy was performed. The histological results confirmed the presence of irregular dilated tortuous arteries and veins, and a retention cyst with epithelial cell lining. We experienced a rare case of a 45-year-old-Korean male who had acute pancreatitis associated with pancreatic AVM. Pancreatic AVM is extremely rare; even rarer is its association with pancreatitis.

Korean J Pancreas Biliary Tract 2018;23(3):116-121

Keywords: Pancreas, Arteriovenous malformations, Pancreatitis, Retention cyst

\author{
Received Jan. 30, 2018 \\ Revised Mar. 24, 2018 \\ Accepted Mar. 25, 2018
}

Corresponding author : Jae Kwang Lee

Division of Gastroenterology and Hepatology, Department of Internal Medicine, Daegu Fatima Hospital, 99 Ayang-ro, Dong-gu, Daegu 14005, Korea

Tel. +82-53-940-7191 Fax. +82-53-954-7417

E-mail; ljkvic33@naver.com

This is an Open Access article distributed under the terms of the Creative Commons Attribution Non-Commercial License (http:// creativecommons.org/licenses/by-nc/3.0/) which permits unrestricted non-commercial use, distribution, and reproduction in any medium, provided the original work is properly cited.

Copyright $\odot 2018$ by The Korean Journal of Pancreas and Biliary Tract

\section{INTRODUCTION}

An arteriovenous malformation (AVM) is a composite tangle of abnormal arteries and veins linked by one or more direct communications called a fistula or shunt. Pancreatic AVM is defined as a tumorous formation or vascular anomaly built up via an aberrant bypass anastomosis of the arterial and venous systems in the pancreas. ${ }^{1}$ Pancreatic AVM is an exceedingly rare condition and the true prevalence of the disease remains unknown. ${ }^{2}$ Pancreatic AVM is mostly con- genital and may be found without symptoms, but it may be discovered during a medical examination due to symptoms such as gastrointestinal bleeding or abdominal pain. Herein we report a case of acute pancreatitis due to pancreatic AVM with a retention cyst, in a 45-year-old-Korean male, which was successfully treated by surgical resection. We also review the literature relating to pancreatic AVM. 


\section{CASE}

A 45-year-old Korean male was admitted to our hospital with symptom of epigastric pain for the past 5 days. He had been experiencing intermittent epigastric discomfort for the previous 2 months. He had no other medical history. He had no history of operation or trauma. No relevant family history, including diabetes and pancreatitis, was found.

At the time of admission, the patient had an acute ill appearance, consciousness was clear, blood pressure was 130/80 $\mathrm{mmHg}$, pulse rate was 72 beats/min, and body temperature was $36.5^{\circ} \mathrm{C}$. The conjunctiva was not pale, and sclera had no jaundice. There were no specific details on chest auscultation, and heart sounds were regular. An abdominal examination revealed mild tenderness in the epigastric area and no other abnormal findings. He did not drink alcohol and had a 20 pack-years history of smoking. Laboratory studies revealed a white blood cell count of $14,410 / \mathrm{mm}^{3}$, a hemoglobin concentration of $18.3 \mathrm{~g} / \mathrm{dL}$, and a platelet count of $270,000 / \mathrm{mm}^{3}$. The result of liver tests are as follow: total bilirubin $0.99 \mathrm{mg} / \mathrm{dL}$, alkaline phosphatase $75 \mathrm{IU} / \mathrm{L}$, aspartate aminotransferase 16 IU/L, alanine aminotransferase $34 \mathrm{IU} / \mathrm{L}$, total protein $7.4 \mathrm{~g} / \mathrm{dL}$, and albumin 4.5 g/dL. Amylase and lipase were elevated to $483 \mathrm{U} / \mathrm{L}$ and 492 $\mathrm{U} / \mathrm{L}$ respectively. Triglyceride was $94 \mathrm{mg} / \mathrm{dL}$. Serum electrolytes and coagulation were within normal range. The tumor
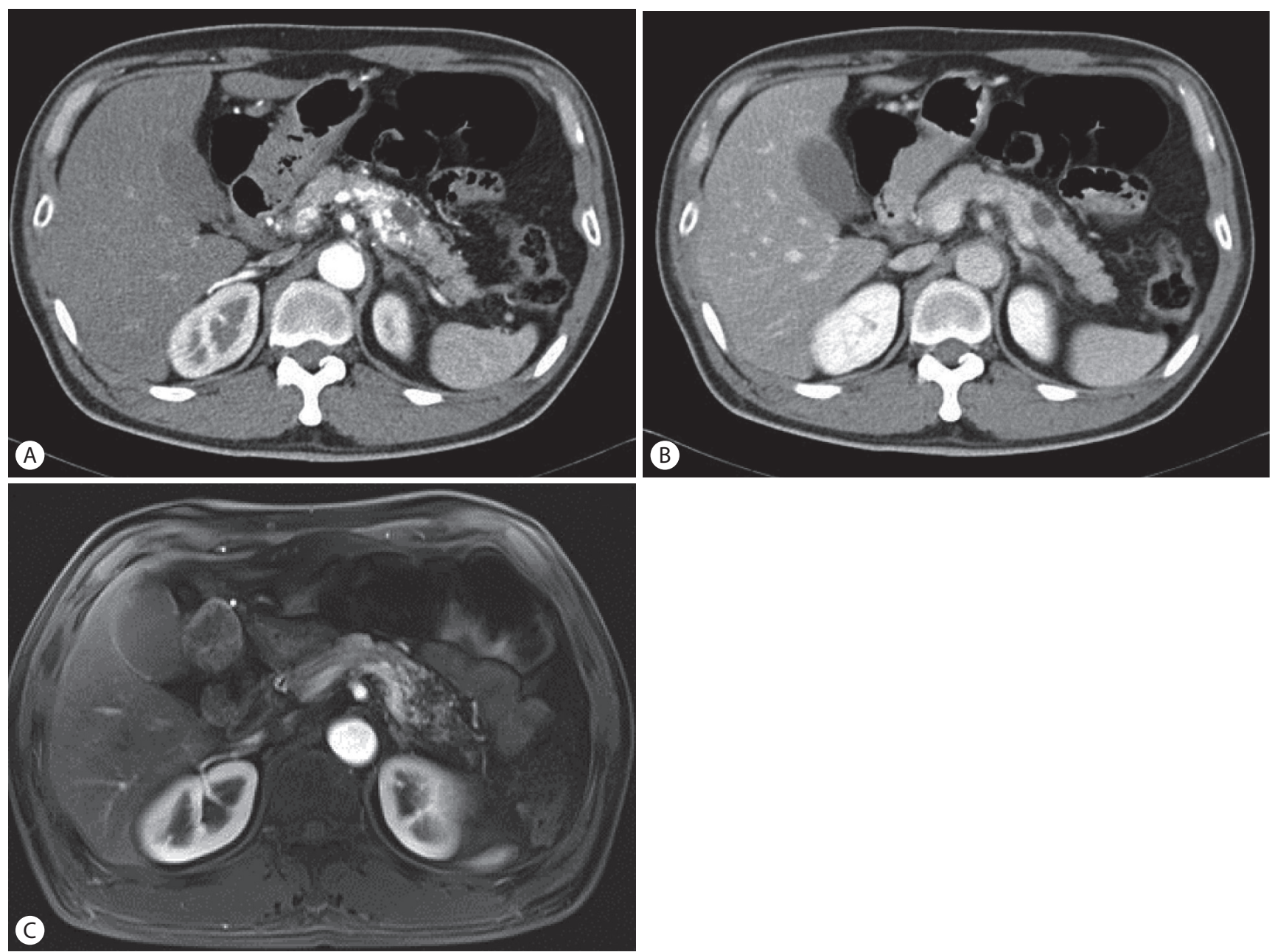

Fig. 1. Contrast enhanced abdominal CT and MRI. A contrast enhanced CT scan of the abdomen showed that irregular dilated vessels with a cystic lesion in the pancreatic body appeared on the arterial phase (A). Contrast enhancement of irregular vessels in the pancreatic body disappeared on the portal phase (B). An MRI scan of the abdomen showed a strong enhancement of the congeries with a signal void in the pancreatic body with a unilocular cystic lesion (C). CT, computed tomography; MRI, magnetic resonance imaging. 
marker test was carbohydrate antigen 19-9 $35.98 \mathrm{U} / \mathrm{mL}$ (reference range, 0-37), and IgG4 was $703 \mathrm{mg} / \mathrm{L}$ (reference range, 30-2,010). On admission 2 days later, a contrast enhanced computed tomography (CT) scan of the abdomen to find the cause of the persistent pain showed suspicious pancreatic swelling in the body to the tail of the pancreas that corresponded to acute pancreatitis CT grade B. Irregular dilated vessels with a cystic lesion in the pancreatic body appeared on the arterial phase (Fig. 1A), but contrast enhancement of irregular vessels in the pancreatic body disappeared on the portal phase (Fig. 1B). A magnetic resonance imaging (MRI) scan of the abdomen on T1-weighted phase showed a strong enhancement of the congeries with a signal void in the pancreatic body with a unilocular cystic lesion (Fig. 1C). These findings suggested a focal acute pancreatitis and pancreatic AVM. Selective angiography was performed to confirm the diagnosis of pancreatic AVM. The angiography showed the proliferation of a vascular network in the pancreatic body and early visualization of the portal vein at the arterial phase (Fig. 2); these findings were compatible with pancreatic AVM. The cause of abdominal pain was diag- nosed by acute pancreatitis caused by pancreatic AVM, and, for definitive treatment of symptomatic pancreatic AVM, distal pancreatectomy with splenectomy was performed. Intraoperatively, the distal portion of the pancreas was diffuse hard, and there was a solid lesion at the body of the pancreas, measuring $4 \times 3 \mathrm{~cm}$. On histologic gross sections, there was an ill-defined solid lesion with abundant vascularity and dilated spaces. The pancreatic duct was grossly unremarkable (Fig. 3A). A microscopic examination of the resected specimen showed hemorrhagic type acute pancreatitis, and a conglomeration of irregular dilated and tortuous arteries and veins in the pancreatic subcapsular tissue and parenchyma (Fig. 3B, C). A cystic lesion at the pancreatic body revealed a retention cyst with epithelial cell lining, which occurs when the pancreatic duct is dilated by obstruction (Fig. 3D). The patient was discharged 21 days after the operation. He tolerated post-surgery recovery well without any complaints of abdominal pain for 6 months of follow-up.
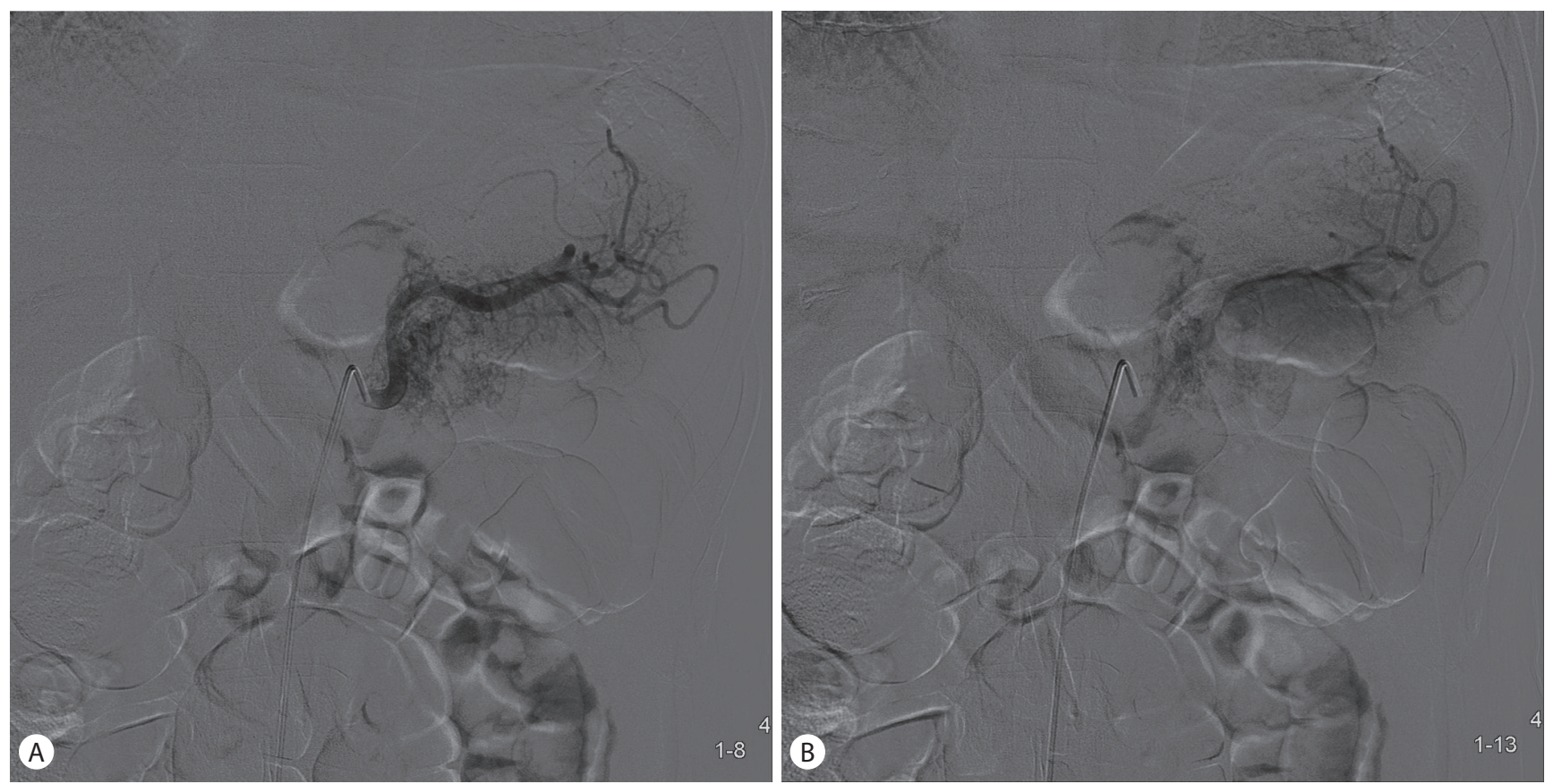

Fig. 2. Selective angiography. The angiography showed the proliferation of a vascular network in the pancreatic body and early visualization of the portal vein at the arterial phase $(A, B)$. 

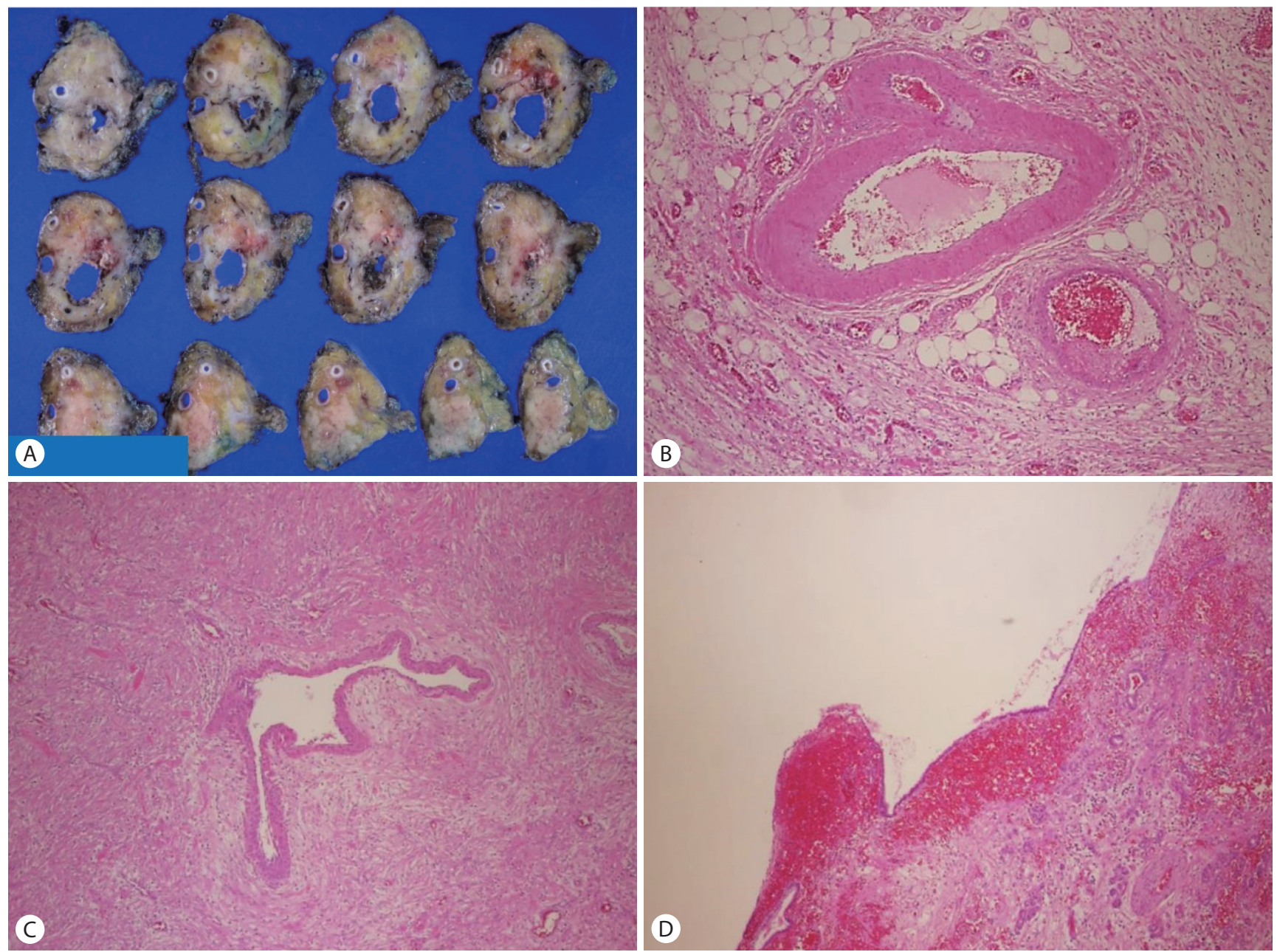

Fig. 3. Pathologic findings. On histologic gross sections, there was an ill-defined solid lesion with abundant vascularity and dilated spaces. The pancreatic duct was grossly unremarkable (A). A microscopic examination of the resected specimen showed hemorrhagic type acute pancreatitis, and a conglomeration of irregular dilated and tortuous arteries and veins in the pancreatic subcapsular tissue and parenchyma $(B: H \& E, \times 50 ; C: H \& E, \times 10)$. A cystic lesion at the pancreatic body revealed a retention cyst with epithelial cell lining ( $D: H \& E, \times 10)$.

\section{DISCUSSION}

AVM in the digestive system is a rare disease, mainly found in the liver. ${ }^{3}$ About $78 \%$ of AVM case of the digestive organs other than the liver were located in the cecum and right colon, followed by jejunum (10.5\%), ileum (5.5\%), duodenum (2.3\%), stomach (1.4\%) and rectum (0.9\%), whereas only $0.9 \%$ were located in the pancreas. ${ }^{3}$ Although the number of reported cases is increasing due to the widespread use of imaging techniques, the true prevalence of the disease is still unknown. In an AVM case series report, the median age at diagnosis was 50 years (range, 7 months to 75 years) with an Asian (78.3\%) and male (88.4\%) predominance. ${ }^{4}$ The portion of the pancreas most frequently involved was the head (59.4\%), followed by the body and tail $(33.3 \%)$, and the entire pancreas $(7.2 \%){ }^{4}$

The etiology of pancreatic AVM is classified as congenital and acquired. Congenital pancreatic AVMs are caused by the abnormal development of the arteriovenous plexus in the embryo, whereas acquired pancreatic AVMs are caused by pancreatitis, tumors, or trauma. A review showed that pancreatic AVM was congenital in more than $90 \%$ of cases. There was also an association with Rendu-Osler-Weber disease in $10-30 \%$ of cases. ${ }^{5}$ In the present case, there was no 
family history of Rendu-Osler-Weber syndrome and no telangiectasia. Also, there was no history of pancreatitis, tumor, or trauma. Therefore, the present case appeared to be a congenital pancreatic AVM rather than AVM associated with Rendu-Osler-Weber disease.

Most patients with pancreatic AVM are asymptomatic. In previous reports, clinical symptoms included varying combinations of gastrointestinal bleeding (47\%), abdominal pain $(41 \%)$, jaundice $(14 \%)$, among other symptoms. ${ }^{2}$ The main symptom of pancreatic AVM is gastrointestinal bleeding associated with portal hypertension. ${ }^{6}$ In a recent study analyzing 89 cases reported in the literature, ${ }^{7}$ it was noted that the most common symptom of pancreatic AVM was gastrointestinal bleeding (47\%), followed by epigastric pain $(46 \%)$. It was also seen that, in the pancreatic head AVM group, bleeding was the most common complication, while in the pancreatic body-tail AVM group, pancreatitis was more common, ${ }^{7}$ as in the present case.

The case of pancreatic AVM with pancreatitis is a reported minority. The pathophysiology of pancreatitis with pancreatic AVM has not yet been clarified. The mechanisms of pancreatitis arising from pancreatic AVM may be classified into three types: i) by bleeding from pancreatic AVM extending into the pancreatic duct, ${ }^{8}$ ii) by ischemic injury due to the pancreatic AVM "stealing" flow from normal surrounding parenchyma like brain $\mathrm{AVM}^{6}{ }^{6}$ iii) by pancreatic duct compression from pancreatic AVM. ${ }^{9}$ In the present case, like in most of the other previously reported case, pancreatic AVM and pancreatitis were detected simultaneously with no history of trauma or tumor in the patient, suggesting that the pancreatic AVM was congenital. In addition, acute pancreatitis was thought to be caused by the third mechanism, because the retention cyst occurring when the pancreatic duct was dilated by obstruction was observed.

Diagnosis is usually confirmed by imaging, because the symptoms are not specific, and the incidence of pancreatic AVM is low. ${ }^{10}$ Radiographic examinations used for pancreatic AVM diagnosis include contrast enhanced CT, abdominal ultrasound, angiography, and MRI. The features of pancreatic AVM identified by multiphase contrast-enhanced
CT include congeries of strong nodular stains and early contrast filling of the portal vein during the arterial phase. ${ }^{2}$ A contrast-enhanced MR study may show similar findings as a dynamic CT study. Further, T1- and T2-weighted images can demonstrate arteriovenous malformation as multiple signal voids. ${ }^{2}$ A definitive diagnosis is established using angiographic evaluation. The angiographic findings of pancreatic AVM are characterized by dilated and tortuous feeding arteries, a racemose intra-pancreatic vascular network followed by a transient dense pancreatic stain, early venous filling (into the portal vein), and early disappearance of the pancreatic stain. ${ }^{11}$ In this case, the findings on CT and angiography were compatible with pancreatic AVM as stated above. Therefore, we could conclude that this case was a congenital AVM of the pancreas, leading to the development of acute pancreatitis.

Owing to the rarity of this disease, there are no standard management protocols and a wide range of strategies including both surgical and non-invasive therapies (e.g., arterial embolization, irradiation, transjugular intrahepatic portosystemic shunt) have been employed in the treatment of symptomatic patients. ${ }^{5}$ Generally, pancreatic AVMs contain multiple feeding arteries, making it difficult to achieve complete embolization or ligation. ${ }^{12}$ Awareness of complication risks caused by embolization, such as bowel ischemia resulting from distal organ embolization, is important. Incomplete treatment of pancreatic AVM such as arterial embolization, can result in growing new collateral vessels and cause the progression of portal hypertension, leading to recurrent gastrointestinal bleeding and/or rupture of the esophageal varices. ${ }^{4}$ Furthermore, it has been reported to be impossible to reduce portal hypertension, once established, even if the pancreatic AVM is surgically removed. ${ }^{5}$ Therefore, the definitive treatment for symptomatic AVM of the pancreas is surgical resection of the affected pancreatic lesion at an early stage, because it eliminates the cause of pain and prevents the development of portal hypertension. ${ }^{4,5}$ When a patient is at a high surgical risk, arterial embolization, irradiation, and transjugular intrahepatic portosystemic shunt are alternative options. ${ }^{4}$ 
In summary, we experienced a rare case of a 45-year-old Korean male who had acute pancreatitis associated with pancreatic AVM, which was diagnosed by dynamic contrast imaging, especially angiography, and successfully treated by surgical resection. Pancreatic AVM is extremely rare; even rarer is its association with pancreatitis. However, pancreatic AVM should be considered as another potential cause of acute pancreatitis.

\section{요 약}

저자들은 조영증강 복부 전산화단층촬영과 혈관조영술로 급성췌장염이 동반된 췌장의 동정맥 기형을 진단하였고 수술적 절제로 치료된 45 세 남성의 예를 경험하였다. 췌장의 동정맥 기형은 매우 드문 질환이며 췌장염이 동반된 것은 더 드물다고 알려져 있다. 그러나췌장의 동정맥 기형도 급성췌장염의 한가지 원인이 될 수 있음을 고려해야 한다.

국문 색인: 췌장, 동정맥기형, 췌장염, 저류낭

\section{Conflicts of Interest}

The authors have no conflicts to disclose.

\section{REFERENCES}

1. Halpern M, Turner AF, Citron BP. Hereditary hemorrhagic telangiectasia. An angiographic study of abdominal visceral angiodysplasias as- sociated with gastrointestinal hemorrhage. Radiology 1968;90:11431149.

2. Ogawa H, Itoh S, Mori Y, Suzuki K, Ota T, Naganawa S. Arteriovenous malformation of the pancreas: assessment of clinical and multislice CT features. Abdom Imaging 2009;34:743-752.

3. Meyer CT, Troncale FJ, Galloway S, Sheahan DG. Arteriovenous malformations of the bowel: an analysis of 22 cases and a review of the literature. Medicine (Baltimore) 1981;60:36-48.

4. Song KB, Kim SC, Park JB, et al. Surgical outcomes of pancreatic arteriovenous malformation in a single center and review of literature. Pancreas 2012;41:388-396.

5. Nishiyama R, Kawanishi Y, Mitsuhashi H, et al. Management of pancreatic arteriovenous malformation. J Hepatobiliary Pancreat Surg 2000;7:438-442.

6. Kanno A, Satoh K, Kimura K, et al. Acute pancreatitis due to pancreatic arteriovenous malformation: 2 case reports and review of the literature. Pancreas 2006;32:422-425.

7. Chou SC, Shyr YM, Wang SE. Pancreatic arteriovenous malformation. J Gastrointest Surg 2013;17:1240-1246.

8. Ohtani N, Kimoto K, Yoshida S, Tanaka T, Inokuchi H, Kawai K. Pancreatic arteriovenous malformation with pancreatitis involving a pancreatico-venous fistula. Gastroenterol Jpn 1992;27:115-120.

9. Choi JK, Lee SH, Kwak MS, et al. A case of recurrent acute pancreatitis due to pancreatic arteriovenous malformation. Gut Liver 2010;4:135139.

10. Rezende MB, Bramhall $S$, Hayes $T$, et al. Pancreatic arteriovenous malformation. Dig Surg 2003;20:65-69.

11. Chuang VP, Pulmano CM, Walter JF, Cho KJ. Angiography of pancreatic arteriovenuos malformation. AJR Am J Roentgenol 1977;129:10151018.

12. Koito K, Namieno T, Nagakawa T, et al. Congenital arteriovenous malformation of the pancreas: its diagnostic features on images. Pancreas 2001;22:267-273. 